\title{
PENGEMBANGAN JARINGAN INTERNET WIRELESS DENGAN WIFI OVERVIEW PADA OBYEK WISATA BLANGSINGA WATERFALL
}

\author{
I Made Ari Dwi Suta Atmaja ${ }^{1)}$, I Nyoman Gede Arya Astawa ${ }^{2)}$, Putu Gde Sukarata ${ }^{3)}$ \\ Jurusan Teknik Elektro, Politeknik Negeri Bali, Jimbaran, Badung, 80364 \\ E-mail: arisuta@pnb.ac.id
}

\begin{abstract}
Blangsinga Waterfall is one tourist attraction with very extreme geographical conditions, where the area has not covered GSM signals as a result tourists can not access the Internet network. The purpose of this research is to determine the spot of Wireless and Hotspot network infrastructure and then to measure signal strength for tourism area coverage. Based on field analysis determined 3 (three) points for network construction and placement of Access Point as Hotspot. Implementation begins with building a LAN network. Then for scanning channel and signal access point testing used Wifi Overview tool. Signal strength testing is performed around the area of the resort by taking a distance of $5 \mathrm{~m}, 10 \mathrm{~m}$, and $15 \mathrm{~m}$ in all directions from the Access point is placed. The result is the establishment of internetworking for Blangsinga Waterfall tourism area. The next result is the internet access where all the tourist areas are covered wifi signal. With the development of internet infrastructure, tourists get easier communication access and management of tourist attractions can develop other facilities based on internet network that has been built.
\end{abstract}

Keywords: Blangsinga Waterfall, Wireless, Wifi Overview, Hotspot, Internet

\begin{abstract}
Abstrak
Blangsinga Waterfall merupakan salah satu objek wisata dengan kondisi geografis yang sangat ekstrim, Dimana area tersebut belum tercover sinyal GSM akibatnya wisatawan tidak bisa mengakses jaringan internet. Tujuan penelitian ini adalah menentukan spot infrastruktur jaringan Wireless serta Hotspot dan kemudian melakukan pengukuran kekuatan sinyal untuk coverage areal wisata. Berdasarkan analisa lapangan ditentukan 3 (tiga) titik untuk pembangunan jaringan dan penempatan Access Point sebagai Hotspot. Implementasi diawali dengan membangun jaringan LAN. Kemudian untuk scanning channel dan pengujian sinyal access point digunakan tools Wifi Overview. Pengujian kekuatan sinyal dilakukan di sekitar areal tempat wisata dengan mengambil jarak $5 \mathrm{~m}$, $10 \mathrm{~m}$, dan $15 \mathrm{~m}$ ke segala arah dari Access point ditempatkan. Hasil yang dicapai adalah terbangunnya internetworking untuk areal wisata Blangsinga Waterfall. Hasil berikutnya adalah adanya akses internet dimana semua areal wisata ter-cover sinyal wifi. Dengan terbangunnya infrastruktur internet, wisatawan mendapatkan akses komunikasi lebih mudah serta pengelola tempat wisata dapat mengembangkan fasilitas lain dengan berdasar jaringan internet yang sudah dibangun.
\end{abstract}

Kata Kunci: Blangsinga Waterfall, Wireless, Wifi Overview, Hotspot, Internet

\section{PENDAHULUAN}

Bidang pariwisata merupakan salah satu sektor potensi suatu daerah khususnya di Bali. Pariwisata di Bali sangat beragam dan sangat terkenal di dunia. Objek wisata Blangsinga Waterfall merupakan salah satu obyek wisata yang sangat terkenal dimana memiliki kondisi gegrafis yang sangat ekstrim. Kondisi obyek wisata Blangsinga yang jauh dibawah merupakan suatu kendala, dimana sinyal GSM tidak ter-cover sama sekali akibatnya wisatawan kesulitan untuk akses komunikasi serta akses jaringan internet Berdasarkan masalah diatas maka penelitian ini akan merancang dan membangun infrastruktur jaringan internet menggunakan wireless di Obyek Wisata Blangsinga Waterfall sehingga diharapkan dengan terbangunnya internetworking dapat memudahkan akses komunikasi dan penyebaran informasi mengenai obyek wisata Blangsinga. 


\section{TINJAUAN PUSTAKA}

Perkembangan teknologi membuat masyarakat tidak bisa lepas dari internet, maka dari itu di tempattempat seperti kampus-kampus atau perkantoran disediakan fasilitas hotspot. Hotspot sendiri adalah lokasi dimana pengguna (user) dapat mengakses internet melalui mobile computer (seperti laptop atau smart phone) tanpa menggunakan koneksi kabel. Jaringan hotspot adalah menggunakan jaringan wireless yang menggunakan radio frekuensi untuk melakukan komunikasi antara perangkat komputer dengan access point (Purwanto, 2015).

\subsection{Protokol Jaringan}

Protokol adalah sebuah aturan atau standar yang mengatur atau mengijinkan terjadinya hubungan, komunikasi, dan perpindahan data antara dua atau lebih titik komputer (Sukaridhoto, 2014).

Protokol merupakan himpunan aturan-aturan yang memungkinkan komputer satu dapat berhubungan dengan komputer lain. Aturan-aturan ini meliputi tatacara bagaimana agar komputer bisa saling berkomunikasi, biasanya berupa bentuk (model) komunikasi, waktu (saat berkomunikasi), barisan (traffict saat berkomunikasi), pemeriksaan error saat transmisi data, dan lain-lain (Syafrizal, 2018).

\subsection{Jenis Jaringan Komputer}

a. Local Area Network (LAN) adalah jaringan komputer yang jaringannya hanya mencakup wilayah kecil; seperti jaringan komputer kampus, gedung, kantor, dalam rumah, sekolah atau yang lebih kecil. Saat ini, kebanyakan LAN berbasis pada teknologi IEEE 802.3 Ethernet menggunakan perangkat switch, yang mempunyai kecepatan transfer data 10, 100, atau 1000 Mbit/s (Sukaridhoto, 2014). Selain teknologi Ethernet, saat ini teknologi 802.11b (Wi-fi) juga sering digunakan untuk membentuk LAN. Tempat-tempat yang menyediakan koneksi LAN dengan teknologi Wi-fi biasa disebut hotspot.

b. Wide Area Network (WAN) adalah singkatan dari istilah teknologi informasi dalam bahasa Inggris: Wide Area Network merupakan jaringan komputer yang mencakup area yang besar (Sukaridhoto, 2014). sebagai contoh yaitu jaringan komputer antar wilayah, kota atau bahkan negara, atau dapat didefinisikan juga sebagai jaringan komputer yang membutuhkan router dan saluran komunikasi publik. WAN digunakan untuk menghubungkan jaringan lokal yang satu dengan jaringan lokal yang lain, sehingga pengguna atau komputer di lokasi yang satu dapat berkomunikasi dengan pengguna dan komputer di lokasi yang lain.

c. Metropolitan area network (MAN). Suatu jaringan dalam suatu kota dengan transfer data berkecepatan tinggi, yang menghubungkan berbagai lokasi seperti kampus, perkantoran, pemerintahan, dan sebagainya. Jaringan MAN adalah gabungan dari beberapa LAN. Jangkauan dari MAN ini antar 10 hingga $50 \mathrm{~km}$, MAN ini merupakan jaringan yang tepat untuk membangun jaringan antar kantor-kantor dalam satu kota antara pabrik/instansi dan kantor pusat yang berada dalam jangkauannya.

\subsection{Wifi Overview}

WiFi Overview merupakan salah satu Tools jaringan yang digunakan secara spesifik dalam Wireless Lan. Wifi Overview berfungsi tidak hanya sebagai WiFI-Scanner, tetapi memiliki fungsi untuk tools jaringan yang lebih banyak. Aplikasi ini bisa dikatakan sebagai "Swiss Army Knife" untuk jaringan WiFi. Dengan alat ini kita dapat mengatur dan mengoptimalkan jaringan nirkabel yang kita gunakan dan dengan satu tampilan, kita akan mendapatkan informasi terperinci tentang jaringan $\mathrm{WiFi}$ (nama WiFi (SSID), kekuatan sinyal, nomor saluran, security yang digunakan dan banyak lagi) di lingkungan Anda.

Salah satu fungsi dari Wifi Overview Tab "Ch Check" (Pemeriksa Saluran) dan "Ch. Radar" (Radar Saluran) adalah dapat digunakan untuk mengoptimalkan jaringan WiFi kita sendiri. Untuk kinerja terbaik, jaringan kita harus menggunakan saluran atau rentang frekuensi yang tidak dimiliki jaringan nirkabel lain atau sesedikit mungkin. WiFi Overview memberi kita pilihan terbaik untuk pemilihan channel atau saluran.

Fungsi yang lain dari Wifi Overview adalah adanya "Detektor WiFi / Sniffer". "WiFi Detector" dapat memberikan informasi mengenai Jaringan $\mathrm{WiFi}$ yang terbuka, memberi notifikasi (suara,teks pop-up, getar dan text-to-speech) dan bisa terhubung secara otomatis. Fitur utamanya adalah Detektor WiFi pencari jaringan terbuka yang kuat (hanya versi Pro). Quick Connect Shortcut dimana kita dapat mengatur jalan pintas untuk berpindah / terhubung dengan cepat dan mudah antara / ke jaringan WiFi lainnya. Merubah prioritas WiFi secara manual. Pemindai WiFi atau Wifi Scanner. Pilihan filtering WiFi untuk "kekuatan", "menurut abjad", "saluran" dan "open / known WiFi". Aktivasi WiFi otomatis saat startup dan otomatis matikan di akhir. Cara manual untuk menambahkan jaringan. Informasi jaringan $\mathrm{WiFi}$ terperinci. Representasi grafis dari semua jaringan nirkabel di sekitar kita. Checker saluran untuk pilihan saluran terbaik yang akan digunakan.

\section{METODE PENELITIAN}

\subsection{Rancangan Penelitian}

Perancangan dan implementasi jaringan wireless di obyek wisata Blangsinga Waterfall berdasarkan gambar situasi obyek wisata Blangsinga Waterfall seperti ditunjukan pada gambar 1 . 


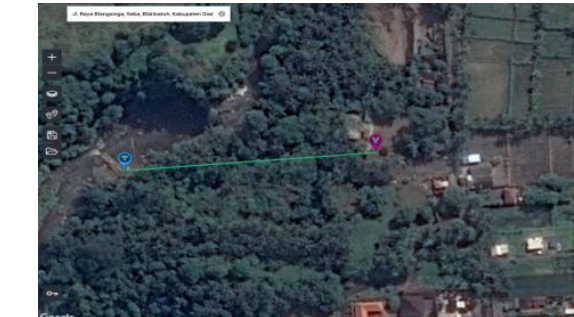

Gambar 1. Lokasi obyek wisata Blangsinga Waterfall

(Sumber : Map Airlink Ubiquiti)

Gambar 1. menunjukkan lokasi obyek wisata Blangsinga Waterfall di ambil dari aplikasi Google maps. Letak air terjun jaraknya kurang lebih 200 meter dari tempat ticketing dan menuruni tangga kurang lebih 87 meter kebawah menuju sungai, seperti Gambar 2. dibawah

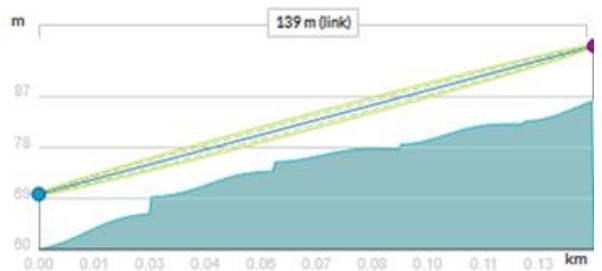

Gambar 2. Ketinggian geografis obyek wisata Blangsinga Waterfall

(Sumber : Map Airlink Ubiquiti)

Berdasarkan gambar lokasi dan ketinggian geografis obyek wisata Blangsinga Waterfall maka tahapan kerja penelitian dilakukan seperti Gambar 3 .

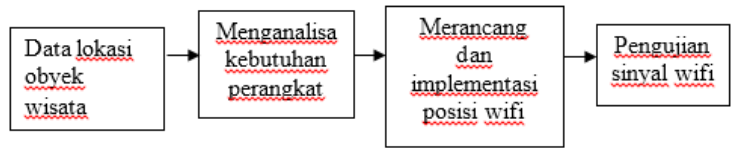

Gambar 3. Tahapan Kerja Penelitian

(Sumber : Hasil Perancangan)

Tahapan kerja penelitian :

1. Persiapan Data: data yang digunakan adalah data lokasi obyek wisata dengan menggunakan google maps dan melihat langsung lokasi penelitian.

2. Analisa kebutuhan perangkat : dengan mengetahui kondisi dilapangan maka dilakukan analisa perangkat yang akan digunakan seperti pemilihan jenis access point yang memiliki kemampuan menyebarkan sinyal wifi, kemudian dihitung kebutuhan peralatan seperti jenis media kabel yang dibutuhkan, jumlah konektor, jumlah switch, jumlah perangkat access point.

3. Merancang posisi wifi : langkah berikutnya adalah merancang posisi wifi dimana untuk analisa awal digunakan software simulasi airLink Ubiquiti kemudian dilakukan pemasangan jaringan wifi dengan access point sehingga bisa mengcover semua area yang dikunjungi oleh wisatawan.
4. Pengujian sinyal wifi: pada tahap ini akan membahas tentang implementasi jaringan wireless berdasarkan proses perancangan yang telah dibangun sebelumnya. Pembahasan dalam tahap ini meliputi pengujian sinyal wifi dengan software simulasi Wifi Overview dan spesifikasi perangkat, batasan implementasi, dan implementasi dengan menguji sinyal wifi.

\section{IMPLEMENTASI DAN PENGUJIAN}

Bab implementasi ini akan membahas tentang implementasi pengembangan jaringan wireless dengan Wifi Overview pada obyek wisata Blangsinga Waterfall. Pembahasan dalam tahap ini meliputi analisa sinyal wifi, penentuan spot Access point, spesifikasi perangkat, pembangunan infrastruktur, dan implementasi pengujian infrastruktur. Pemetaan lokasi Obyek wisata ditunjukkan pada Gambar 4.

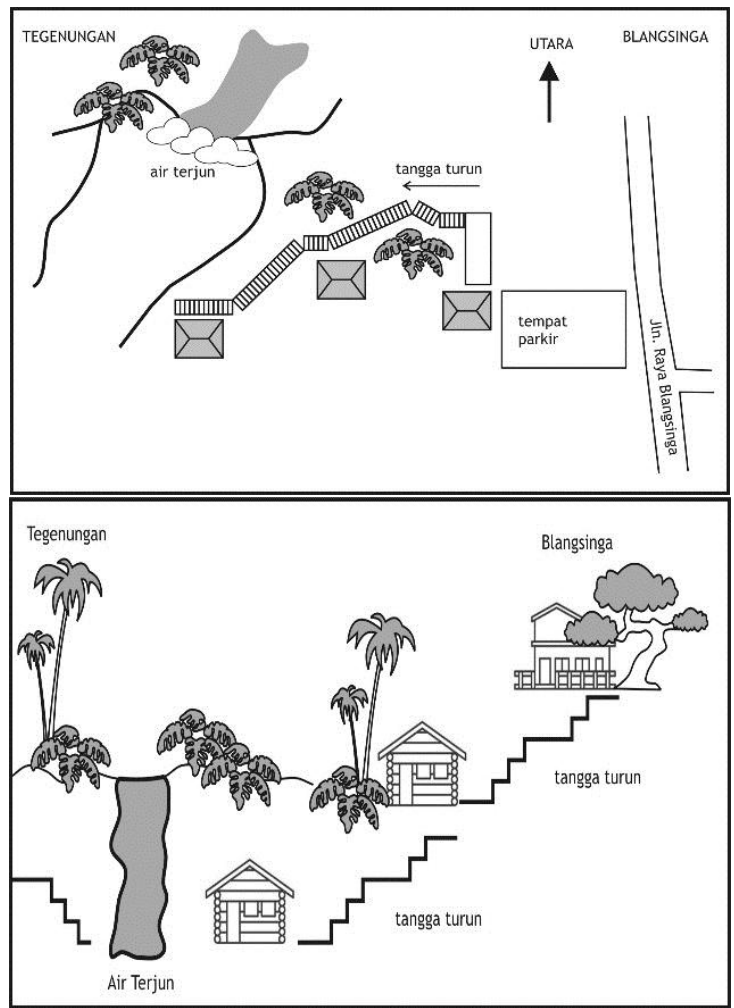

Gambar 4. Pemetaan Areal Blangsinga Waterfall (Sumber : Hasil Perancangan)

Di dalam Gambar 4. terlihat ada 3 tempat yang digunakan sebagai pos tiket serta pos keamanan untuk menjaga areal objek wisata. Dari Pos atas menuju ke pos berikutnya menuruni tangga yang cukup curam dengan jarak antar pos kurang lebih $125 \mathrm{~m}$.

\subsection{Implementasi}

\subsubsection{Test Jaringan Wireless Eksisting}

Hasil dari test jaringan wireless eksisting pada areal obyek wisata akan menjadi acuan dalam mengimplementasikan spot-spot penempatan access point yang tepat sehingga tidak terjadi interferensi 
antara acces point satu dengan yang lainnya. Dari keseluruhan areal objek wisata, pengujian jaringan wireless eksisting dilakukan di tempat tempat yang ramai dikunjungi turis. Spot pengujian jaringan wireless eksisting ditunjukkan pada gambar 5 .

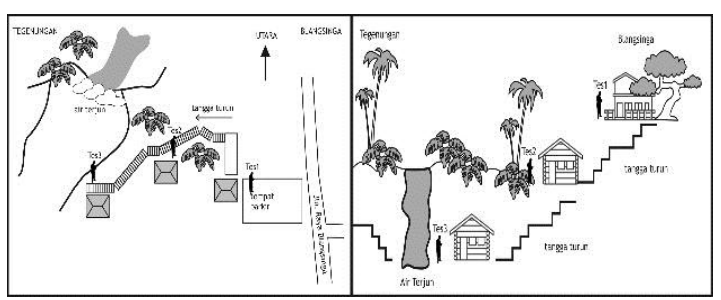

Gambar 5. Spot Pengujian Jaringan Wireless Eksisting 1

Pada proses pengujian awal dilakukan pada 2 (dua) tempat. Dimana 2 (dua) tempat tersebut merupakan tempat yang paling ramai dikunjungi oleh turis. Hasil pengujian awal pada kondisi jaringan wireless eksisting ditunjukkan pada gambar 6 .

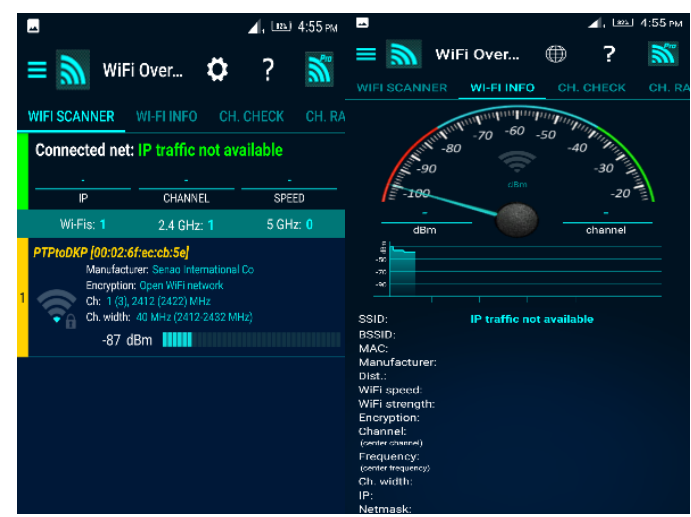

Gambar 6. Scanner Wifi Existing dan Wifi Info

Hasil uji dengan Wifi Overview baik pada spot tes1, spot test 2 dan spot test 3 terlihat bahwa areal obyek wisata belum ter-cover sinyal wifi yang bisa digunakan oleh turis maupun pengelola disana. Dalam hasil uji pada Wifi Overview terlihat ada 1 hotspot yang di miliki orang lain dengan kualitas Implementasi Infrastruktur LAN.

Implementasi insfrastruktur diawali dengan pemasangan kabel LAN dari Titik 1 ke Titik 2 sepanjang $125 \mathrm{~m}$ kemudian di Titik 2 di pasangkan Box Panel dimana didalamnya ditempatkan Switch 8 port untuk dapat membagi jaringan ke Access Point yang akan dipasang. Selanjutnya dari Titik 2 ke Titik 3 ditarik kabel kembali sepanjang $125 \mathrm{~m}$ dan pada Titik 3 yaitu pos terbawah dipasangkan kembali Box Panel yang juga didalamnya ditempatkan switch 8 port untuk nantinya pada tahap implementasi selanjutnya akan di pasang Access Point kedua.

\subsubsection{Implementasi Jaringan Wireless}

Implementasi pengembangan Jaringan Wireless dilakukan berdasarkan hasil pengujian awal yang telah dilakukan sebelumnya. Implementasi infrastruktur dilakukan pada 2 titik berdasarkan spot lokasi turis berkunjung. Spot implementasi tersebut ditunjukkan oleh Gambar 7.

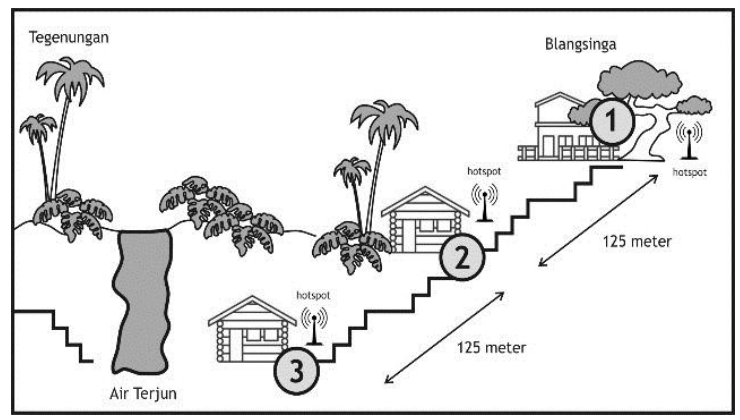

Gambar 7. Spot Implementasi Jaringan Wireless

Untuk pemilihan channel yang akan digunakan pada jaringan wireless yang dibangun, maka dilakukan scanning dengan Wifi Overview untuk mengetahui Free Channel yang memungkinkan untuk digunakan oleh Access Point yang di pasang. Dengan melakukan scanning kita dapat dengan lebih tepat menentukan channel yang akan digunakan sehingga mencegah terjadinya interferensi terhadap frequensi sinyal lain. Informasi Free Channel yang bisa dipilih ditunjukkan oleh Gambar 8. dibawah ini.

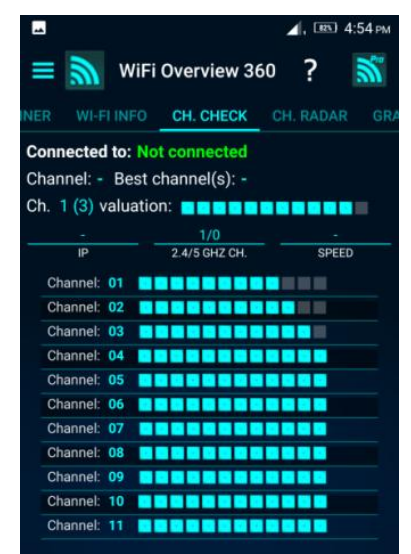

Gambar 8. Informasi Free Channel hasil Scanning

Untuk penamaan Hotspot pada Titik 1 dan Titik 2 adalah sesuai dengan instruksi dari pengelola tempat wisata. Konfigurasi yang dilakukan untuk Hotspot adalah sebagai berikut . SSID : Blangsinga Waterfall, Channel: 13 ( $2472 \mathrm{Mhz}$ ), Security : WPA2, DHCP Client : Network 192.168.1.0/24 ( IP : 192.168.1.1 s/d 192.168.1.254).

Untuk konfigurasi Access point untuk Titik 2 dilakukan dengan konfigurasi yang sama seperti Access Point Titik 1.

\subsection{Pengujian Sinyal}

Setelah konfigurasi berhasil diselesaikan kemudian dilakukan pengukuran sinyal tahap awal untuk mengetahui keberhasilan konfigurasi yang telah dilakukan. Gambar 9.a, Gambar 9.b dan Gambar 9.c menunjukkan hasil pengukuran sinyal wifi dari jarak $10 \mathrm{~m}, 15 \mathrm{~m}$ dan 20m terhadap Access Point yang telah berhasil di psang dan di konfigurasi. 


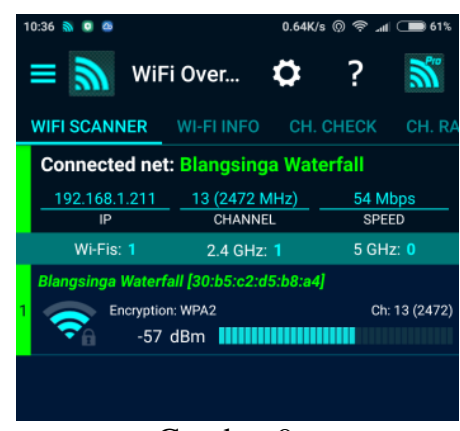

Gambar 9.a

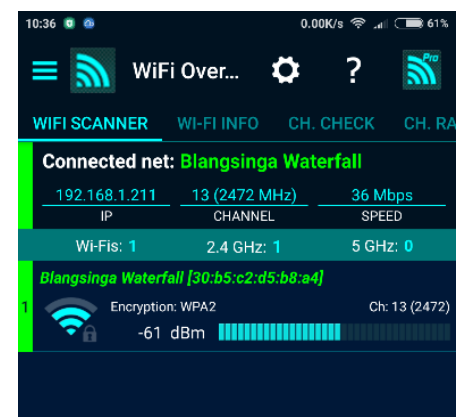

Gambar 9.b

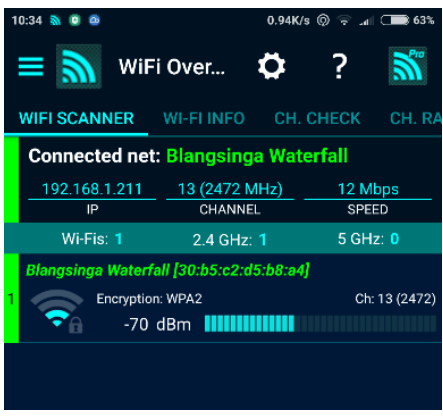

Gambar 9.c

Gambar 9. Hasil Pengukuran Sinyal

Dari hasil pengukuran sinyal dapat terlihat bahwa dengan jarak pengukuran terjauh yaitu $20 \mathrm{~m}$ coverage sinyal mulai melemah namun untuk akses komunikasi dan internet masih dapat berjalan dengan baik. Dari pengukuran sinyal yang di hasilkan bahwa penempatan Access Point sebagai hotspot sudah tepat karena lebar areal wisata di sekitaran air terjun tidak lebih dari 20m sehingga akses internet dapat dinikmati oleh turis yang berwisata di sekitaran Blangsinga Waterfall.

\section{SIMPULAN DAN SARAN}

Simpulan dari penelitian ini adalah analisa lapangan dan pengujian kondisi existing sangatlah penting untuk dapat menentukan efektifitas pembangunan infrastruktur jaringan internet, apalagi dengan kondisi yang cukup ekstrim. Selain itu pengujian kekuatan sinyal sangat dibutuhkan untuk dapat menentukan luasan coverage area yang dapat mengakses jaringan internet.

Saran yang dapat diberikan dari penelitian ini adalah dilakukannya riset akan durability dari kemampuan alat yang terpasang mengingat kondisi geografis dan kondisi alam yang sangat ekstrem. Selain itu perlu dilakukan network assestmet dalam jangka untuk mengetahui bandwith internet yang diperlukan untuk mengakomodasi kebutuhan internet oleh wisatawan dan pengelola tempat wisata.

\section{DAFTAR PUSTAKA}

[1] Andikasani, M.R., M. Awaluddin, \& A. Suprayogi (2014) Aplikasi Persebaran Objek Wisata Di Kota Semarang Berbasis Mobile Gis Memanfaatkan Smartphone Android. Jurnal Geodesi Undip. 3(2): p. 28-39.

[2] Bhayangkara, F.J. \& I. Riadi (2014) Implementasi Proxy Server Dan Load Balancing Menggunakan Metode Per Connection Classifier (PCC) Berbasis Mikrotik. Jurnal Sarjana Teknik Informatika. 2(2): p. 1206-1217.

[3] Purwanto, E. (2015) Implementasi Jaringan Hotspot Dengan Menggunakan Router Mikrotik Sebagai Penunjang Pembelajaran (Studi Kasus : SMK Sultan Agung Tirtomoyo Wonogiri). Jurnal INFORMA Politeknik Indonusa Surakarta. 1(2): p. 20-27.

[4] Sukaridhoto, S. (2014) Jaringan Komputer I, Surabaya: Politeknik Elektronika Negeri Surabaya (PENS).

[5] Syafrizal, M. (2018) Teknologi dan Protokol Jaringan. Jurnal Amikom: p. 1-10. 